\title{
INFLUÊNCIA DA PARTICIPAÇÃO EM MAIOR ESCALA DO PELLET FEED DA MINA DE BRUCUTU NO PROCESSO DE PELOTIZAÇÃO VALE-TUBARÃO*
}

\author{
Marcos Meyer ${ }^{1}$ \\ Cátia Casagrande ${ }^{2}$ \\ Luiz Alexandre de Martin ${ }^{3}$ \\ Taciane Zocatelli ${ }^{4}$
}

\section{Resumo}

A pelotização é um processo de aglomeração com objetivo de agregar valor aos finos de minérios de ferro (pellet feed). A partir de 2010, a mina de Brucutu situada no Quadrilátero Ferriferro (QF) passa a ser a maior fornecedora de matéria prima para as plantas de Tubarão / Vitória-ES. O estudo avaliou a performance industrial de duas misturas com alta participação de minério de Brucutu, acima do padrão utilizado na usina de pelotização. Os minérios compostos nas misturas foram caracterizados por análise química, física, mineralógica e microestrutural. O desempenho operacional mostrou superior à mistura padrão utilizada para a produção de pelotas para redução direta, permanecendo com os parâmetros de qualidade consoantes com as especificações do produto final. $O$ conhecimento das características geometalúrgicas destas misturas com minério de Brucutu em maior escala foi de suma importância para adequar o processo e custo das principais operações unitárias da planta envolvida (moagem e forno).

Palavras Chaves: Minério de ferro; Pelotização mineralogia; Pelotas redução direta.

\section{INFLUENCE OF LARGER SCALE OF THE PELLET FEED FROM BRUCUTU MINE IN THE PELLETIZING PROCESS VALE-TUBARÃO}

\begin{abstract}
Pelletizing is an agglomeration process of fine iron ore (pellet feed). From 2010, Brucutu mine in the Quadrilátero Ferrífero (QF) becomes to be the biggest supplier of raw materials for the plants at Tubarão Complex (Brasil - Vitória - ES. The study evaluated the industrial performance of two mixtures with high participation of Brucutu iron ore than the standard mixture used in pelletizing plant. This iron ore and the others from different mines in the QF were characterized by chemical, physical, mineralogical and micro-structural (by optical microscopy) analysis. Operational performance was higher than the standard mixture for direct reduction pellets production, remaining the quality parameters with the product specifications. The Geometallurgical knowledge from the mixtures with larger scale of Brucutu becomes so much important to adapt the process and cost of major unit operations of the plant (grinding and kiln).
\end{abstract}

Keywords: Iron ore; Pelletizing; Mineralogy; Direct reduction pellets.

Engenheiro metalurgista, Unidade Técnica, DIPE, Vale, Vitória, ES, Brasil

Msc, engenheira geólogica, Engenharia de Processo, DIPE, Vale, Vitória, ES, Brasil

Técnico especializado, Unidade Técnica, DIPE, Vale, Vitória, ES, Brasil

Engenheira Metalurgista, Unidade Técnica DIPE, Vale, Vitória, ES, Brasil.

* Contribuição técnica ao 44 Seminário de Redução de Minério de Ferro e Matérias-primas,

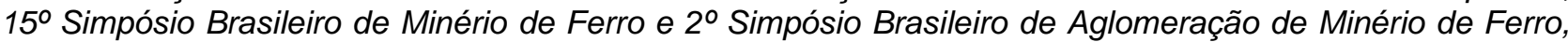
15 a 18 de setembro de 2014, Belo Horizonte, MG, Brasil. 


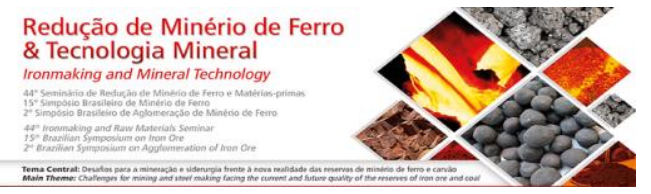

\section{INTROODUÇÃO}

Fruto de um investimento de US\$1,1 bilhão em 2010, Brucutu torna-se a maior mina da Vale no "Sistema Sudeste" com produção de $26 \mathrm{Mt} / a n$ o [1]. Com inicio da operação de novas plantas, a participação do minério de Brucutu foi elevada visando garantir a produtividade das usinas do Complexo de Tubarão e do Oriente Médio.

A pelotização é um processo de aglomeração de finos e endurecimento em forno, sendo compreendido pelas seguintes fases unitárias: empilhamento; cominuição; pelotamento; queima [2]. Essas etapas podem sofrer oscilações de produtividade e qualidade devido às variações intrínsecas da matéria-prima, ou seja, característica mineralógica, microestruturais e parâmetros físicos como superfície específica e granulometria $[3,4,6,8,9]$. A Figura 1 apresenta o fluxograma do processo de pelotização e as respectivas operações unitárias.

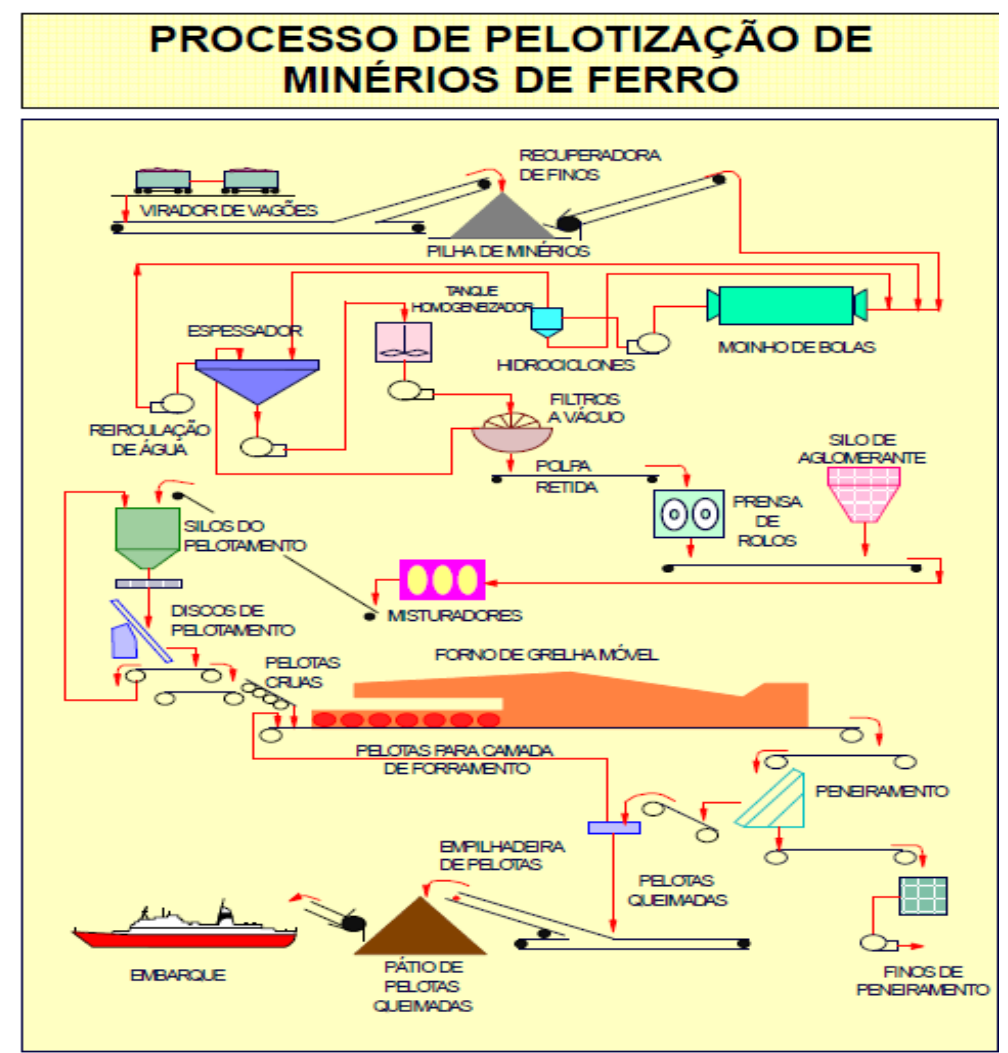

Figura 1. Fluxograma do processo de pelotização de minério de ferro.

Os minérios hematíticos brasileiros apresentam estruturas internas muito variadas devido às diferentes condições geológicas submetidas, ou mesmo, em virtude de sua gênese. Desta forma, originaram-se minérios com diferentes constituintes mineralógicos, trama, tamanho e morfologia dos cristais e poros. Segundo Rosière \& Chemale [5], as formações ferríferas de alto teor de ferro no QF são:

$\checkmark$ Hematiticas: formação ferrífera composta dominantemente por hematita e subordinada por magnetita e goethita, com estrutura maciça, ou bandada ou foliada;

$\checkmark$ Itabiritos: formação ferrífera bandada, metamórfica, constituída essencialmente por quartzo e hematita. Podem ser compactos ou friáveis.

$\checkmark$ Cangas: formações superficiais constituídas por blocos de hematita e itabiritos, soltos ou cimentados por goethita. Estrutura com elevada alteração.

* Contribuição técnica ao 44ํ Seminário de Redução de Minério de Ferro e Matérias-primas, 15은 Simpósio Brasileiro de Minério de Ferro e 2 Simpósio Brasileiro de Aglomeração de Minério de Ferro, 15 a 18 de setembro de 2014, Belo Horizonte, MG, Brasil. 
Roberto [1] demonstrou que o itabirito friável é a tipologia principal das cavas de Brucutu representando $75,48 \%$ e o restante dividido entre hematita goethitica e canga. A caracterização mineralógica dos minérios concentrados nesta mina direcionados para a produção de pelotas para redução direta resultou em hematita, na maioria, goethita, martita e magnetita.

Além de Brucutu, as misturas em Tubarão são compostas por minérios de ferro provenientes dos complexos de Mariana e Itabira. Casagrande [7] demonstrou em escala piloto que o aumento da participação de minério Brucutu não influencia na qualidade física e metalúrgica das pelotas. Sabe-se que em escala piloto os parâmetros operacionais são fixos e as interferências do processo são muito inferiores correlacionando com o processo industrial. Baseado nisso, foi importante replicar o teste em escala industrial.

Meyer [2]; Dwarapudi [8]; Jiang et al [9] desenvolveram trabalhos que correlacionam a mineralogia resultante da pelota queimada com a influência na qualidade física e metalúrgica, no processo operacional e eficiência do forno, sendo que os teores de magnetita e hematita são determinantes para o tratamento térmico da pelota e obtenção de fases minerais.

Este presente trabalho apresenta uma abordagem geometalúrgica entre os minérios de ferro do QF utilizados como matéria prima em Tubarão e os resultados obtidos no processo produtivo de pelotas para redução direta ao adotar diferentes participações do pellet feed de Brucutu nas pilhas de homogeneização. Caracterizações foram realizadas em laboratório e posterior em escala industrial na Usina Itabrasco.

\subsection{Processo de Redução Direta}

O processo de redução direta é uma alternativa ao uso do alto forno. O produto deste processo, ferro esponja, é fabricado com um combustível mais disponível e também mais barato: o gás natural. Sua desvantagem é o menor volume de produção quando comparado com o alto forno, porém representa uma considerável redução de custo de investimento inicial e de energia consumida em situação de menor volume de produção. Embora a produção de ferro esponja tenha oscilado ao longo dos anos, a previsão do início de operação de plantas ao longo do período de 2013 a 2015 deve resultar em um aumento médio na produção de cerca de 5 a 6 milhões de toneladas por ano a partir de $2015-2016[10]$.

\section{MATERIAL E MÉTODOS}

\subsection{Caracterização dos Minérios de Ferro}

Os minérios provenientes de cada complexo foram amostrados separadamente para caracterização detalhada (química, física e mineralógica). Estas amostras, 5 ton de cada tipo, foram coletadas durante o empilhamento nos pátios de minérios em Tubarão.

As análises químicas foram realizadas no laboratório da DIPE através da espectroscopia de fluorescência de raios-X da Rigaku. A caracterização mineralógica foi realizada com suporte de lupa estereoscópica e microscopia ótica na Fundação Gorceix / UFOP. A caracterização física foi determinada pela distribuição granulométrica dos minérios por peneiramento a seco e a superfície específica, que é considerada um dos parâmetros críticos de processo e de produtividade da moagem, foi medida através de permeâmetro Fisher na escala de 0,2 a $50 \mu \mathrm{m}$.

* Contribuição técnica ao 44ํ Seminário de Redução de Minério de Ferro e Matérias-primas, 15 Simpósio Brasileiro de Minério de Ferro e 2ำ Simpósio Brasileiro de Aglomeração de Minério de Ferro, 15 a 18 de setembro de 2014, Belo Horizonte, MG, Brasil. 


\subsection{Elaboração das Misturas}

Com base nas especificações químicas do produto Vale para redução direta, das características químicas, físicas e mineralógicas dos minérios individuais e, por último, nas condições de logística para fornecimento em lotes destes minérios, foram testadas 30 pilhas para cada uma das duas misturas distintas visando avaliar o desempenho do processo operacional de moagem e forno em comparação à mistura padrão. Essas operações unitárias são estratégicas para avaliação dos principais parâmetros de processo que influenciam diretamente na produtividade da planta e qualidade do produto final. A planta envolvida nesta etapa foi a Usina Itabrasco. A Tabela 1 apresenta as formações definidas e o padrão a ser comparado.

Tabela 1. Pilhas com diferentes participações de Brucutu

\begin{tabular}{c|c|c|c}
\hline Minérios & Pilha padrão & Pilha A & Pilha B \\
\hline Brucutu & $25 \%$ & $33 \%$ & $50 \%$ \\
\hline Minério I & $50 \%$ & $33 \%$ & $25 \%$ \\
\hline Minério II & $25 \%$ & $33 \%$ & $25 \%$ \\
\hline
\end{tabular}

O parque de moagem consiste em 02 moinhos cilíndricos com produtividade máxima de $350 \mathrm{t} / \mathrm{h}$; diâmetro de $5,18 \mathrm{~m}$; comprimento de $10,56 \mathrm{~m}$; potência nominal de $2.250 \mathrm{~kW}$; 12,9 RPM; carga de enchimento de bolas de alto cromo (382 t). Foi visada uma superfície específica de $1650 \pm 50 \mathrm{~cm}^{2} / \mathrm{g}$ e granulometria mínima de $80 \%$ menor que $0,045 \mathrm{~mm}$ (parâmetros conforme padrão técnico). Amostras das pilhas $A$ e $B$ foram retiradas na alimentação da moagem durante o processo de produção para caracterização.

O forno de grelha móvel LURGI desta usina possui 451,5 $\mathrm{m}^{2}$ de área, sendo $3,5 \mathrm{~m}$ de largura e $129 \mathrm{~m}$ de comprimento, sendo divididos em: Secagem ascendente 16,5 m; secagem descendente $9,0 \mathrm{~m}$; pré-queima $10,5 \mathrm{~m}$; queima $43,5 \mathrm{~m}$; pós-resfriamento $7,5 \mathrm{~m}$; resfriamento de $42 \mathrm{~m}$. A capacidade específica de produção situa-se na faixa $26-30$ $\mathrm{t} / \mathrm{m}^{2} / \mathrm{dia}$. Possui 05 ventiladores de processo - 01 para a secagem ascendente; 01 para a pré-queima; 01 para a queima; 01 para o resfriamento (todos de $4 \mathrm{MW}$ ); 01 para exaustão (0,8 MW). Através do sistema PIMS (Plant Information Management System), os dados de processos foram compilados, tais como: produtividade moagem, superfície específica e granulometria da polpa retida (pós-filtragem) e qualidade.

\section{RESULTADOS E DISCUSSÃO}

\subsection{Resultados de Caracterização}

As tabelas a seguir apresentam os resultados de caracterização dos minérios por origem.

Tabela 2. Resultados de análise química dos minérios por complexo

\begin{tabular}{cccc}
\hline Parâmetros & Brucutu (\%) & Minério I (\%) & Minério II (\%) \\
\hline $\mathrm{Fe}_{2} \mathrm{O}_{3}$ & 96,70 & 98,49 & 96,58 \\
\hline $\mathrm{SiO}_{2}$ & 1,05 & 0,93 & 0,60 \\
\hline $\mathrm{Al}_{2} \mathrm{O}_{3}$ & 0,38 & 0,18 & 0,47 \\
\hline $\mathrm{P}$ & 0,03 & 0,01 & 0,05 \\
\hline $\mathrm{Mn}$ & 0,04 & 0,13 & 0,10 \\
\hline $\mathrm{CaO}$ & 0,01 & 0,01 & 0,01 \\
\hline $\mathrm{MgO}$ & 0,02 & 0,01 & 0,01 \\
\hline $\mathrm{TiO}_{2}$ & 0,28 & 0,05 & 0,04 \\
\hline Outros & 1,14 & 0,30 & 2,11 \\
\hline
\end{tabular}

* Contribuição técnica ao 44ํ Seminário de Redução de Minério de Ferro e Matérias-primas, 15 Simpósio Brasileiro de Minério de Ferro e 2ำ Simpósio Brasileiro de Aglomeração de Minério de Ferro, 15 a 18 de setembro de 2014, Belo Horizonte, MG, Brasil. 
Redução de Minério de Ferro

Tabela 3. Faixas granulométricas dos minérios por complexo

\begin{tabular}{cccc}
\hline Faixas granulométricas $(\mathrm{mm})$ & Brucutu (\%) & Minério I (\%) & Minério II (\%) \\
\hline$>0,300$ & 1,73 & 0,92 & 1,77 \\
\hline$>0,106$ & 22,70 & 5,86 & 17,28 \\
\hline$>0,075$ & 19,43 & 10,79 & 15,11 \\
\hline$>0,045$ & 30,73 & 35,03 & 28,96 \\
\hline$<0,045$ & 25,24 & 47,78 & 36,63 \\
\hline Tabela 4. Parâmetros físicos por origem & Brucutu & Minério I & Minério II \\
\hline Parâmetros físicos & 350 & 410 & 409 \\
\hline Superfície Específica $\left(\mathrm{cm}^{2} / \mathrm{g}\right)$ & 2,23 & 1,40 & 3,01 \\
\hline İndice de Moabilidade $\left(\mathrm{cm}^{2} / \mathrm{gWh}\right)$ & 1,02 & 0,30 & 2,11 \\
\hline PPC (\%) & & &
\end{tabular}

Os minérios individuais foram submetidos à caracterização mineralógica e microestrutural qualitativa e quantitativa. A Tabela 5 apresenta o resultado dos minérios individuais.

Tabela 5. Análise mineralógica e microestrutural por origem

\begin{tabular}{lccc}
\hline \multicolumn{1}{c}{ Mineralogia } & Brucutu $(\%)$ & Minério I (\%) & Minério II (\%) \\
\hline Hematita tabular monocristalina & 57,27 & 56,63 & 27,37 \\
\hline Hematita tabular policristalina & 2,79 & 1,96 & 0,24 \\
\hline Hematita tabular & 60,06 & 58,59 & 27,61 \\
\hline Hematita granular monocristalina & 15,54 & 28,80 & 6,66 \\
\hline Hematita granular policristalina & 0,20 & 0,48 & 0,61 \\
\hline Hematita granular & 15,74 & 29,28 & 7,27 \\
\hline Hematita lobular policristalina & 0,88 & 10,63 & 0,31 \\
\hline Hematita & 76,68 & 98,5 & 35,19 \\
\hline Martita & 5,61 & 0,07 & 35,96 \\
\hline Magnetita & 1,34 & 0,02 & 9,18 \\
\hline Goethita & 14,49 & 0,40 & 18,79 \\
\hline Outros/Quartzo & 1,88 & 1,01 & 0,88 \\
\hline Tamanho médio $(\mu \mathrm{m})$ & 66 & 49 & 24 \\
\hline
\end{tabular}

Comparando a participação de hematita tabular entre os minérios de ferro individuais, os minérios de Brucutu e "I" apresentam em maior quantidade do que o minério II. Essa morfologia de grãos alongados sugere impacto negativo com relação à eficiência do peneiramento. A passagem de grão com a referida morfologia por uma dada malha de peneira requer uma posição espacial específica, conforme ilustrado na Figura 2.
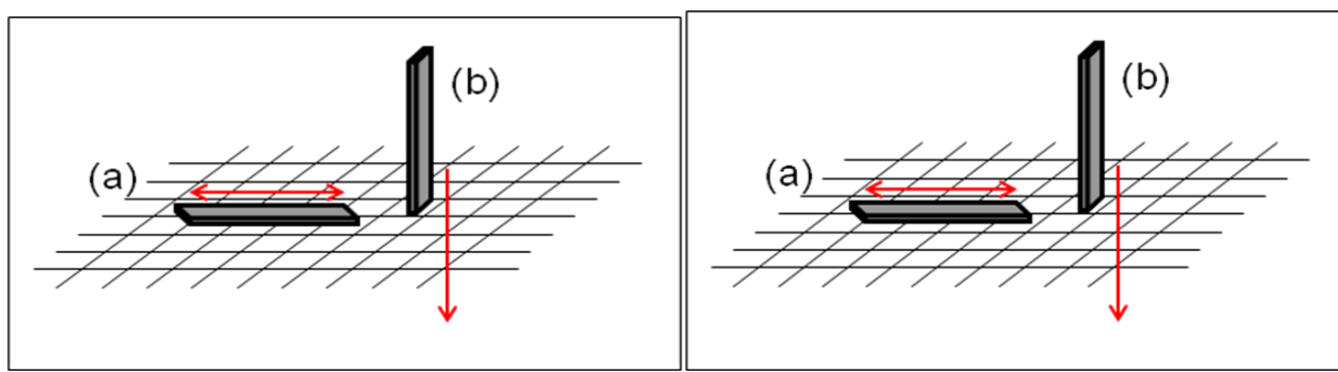

Figura 2: Relação entre a posição espacial da morfologia tabular retida (a) e passante (b), em uma hipotética malha de peneira.

De acordo com a tabela 5, o Minério I apresenta maior presença de hematita granular, exigindo maior energia para cominuiçao. Em termos de mineralogia, contata-se em Brucutu a presença de estruturas porosas como martita e goethita demonstrando sua característica peculiar em relação aos produtos concentrados em Itabira, corroborando

* Contribuição técnica ao 44 Seminário de Redução de Minério de Ferro e Matérias-primas, 15 Simpósio Brasileiro de Minério de Ferro e $2^{\circ}$ Simpósio Brasileiro de Aglomeração de Minério de Ferro, 15 a 18 de setembro de 2014, Belo Horizonte, MG, Brasil. 
com a caracterização realizada por Roberto [1]. A presença de materiais mais porosos proporciona uma obtenção de superfície específica com maior produtividade e menor consumo de energia elétrica do parque de moagem [4-7].

Os materiais provenientes Minério II apresentam grande quantidade de minerais porosos, martita e goethita, o que pode influenciar no processo de moagem e filtragem, refletindo nos resultados de índice de moabilidade e PPC mais elevados [4;7]. A presença considerável de magnetita, martita e goethita em conjunto tem influencia direta no processo de tratamento térmico da pelota [6,8-11].

\subsection{Resultados Clindustriais}

As figuras a seguir apresentam os resultados de caracterização mineralógica da amostragem sistemática realizada na alimentação da moagem.
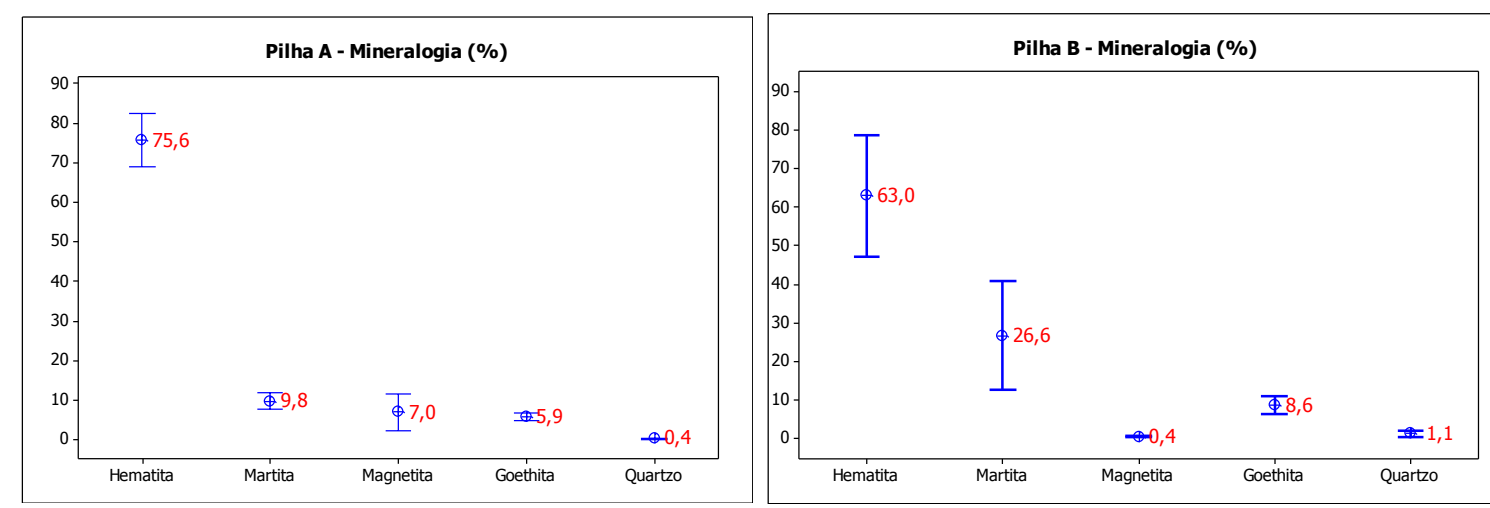

Figura 3. Gráficos da distribuição mineralógica das pilhas testadas.

A elevação considerável dos minerais porosos, principalmente da martita, é proporcional à elevação da participação de Brucutu na pilha $B$ e redução do minério I (vide caracterização na Tabela 5). Do mesmo modo, o mineral compacto (hematita) reduz consideravelmente.

A figura 4 apresenta os resultados de granulometria $(\%<0,045 \mathrm{~mm})$ da polpa retida das pilhas Padrão (Pad), A e B, ao longo dos anos de 2012, 2013 e 2014. Nota-se que a alta participação de hematita granular pode impactar negativamente na moagem, como também a distribuição granulométrica dos minérios individuais.

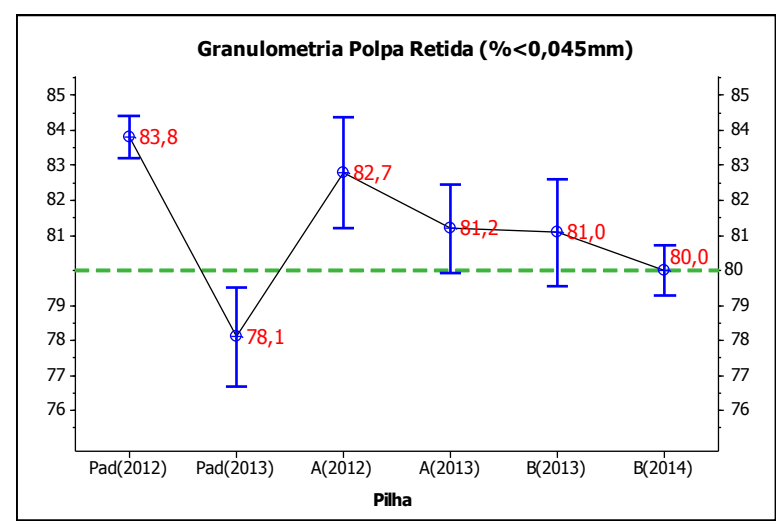

Figura 4. Gráficos do percentual passante na malha de 0,045mm (pós-moagem).

De acordo com a figura 4 , os resultados mostraram que os minérios tornaram-se mais grosseiros, sendo que ocorreu variação de participação hematita granular e tabular. Isto comprova que tanto a caracterização física quanto a mineralógica impactam no processo de moagem.

* Contribuição técnica ao 44 Seminário de Redução de Minério de Ferro e Matérias-primas, 15 Simpósio Brasileiro de Minério de Ferro e $2^{\circ}$ Simpósio Brasileiro de Aglomeração de Minério de Ferro, 15 a 18 de setembro de 2014, Belo Horizonte, MG, Brasil. 

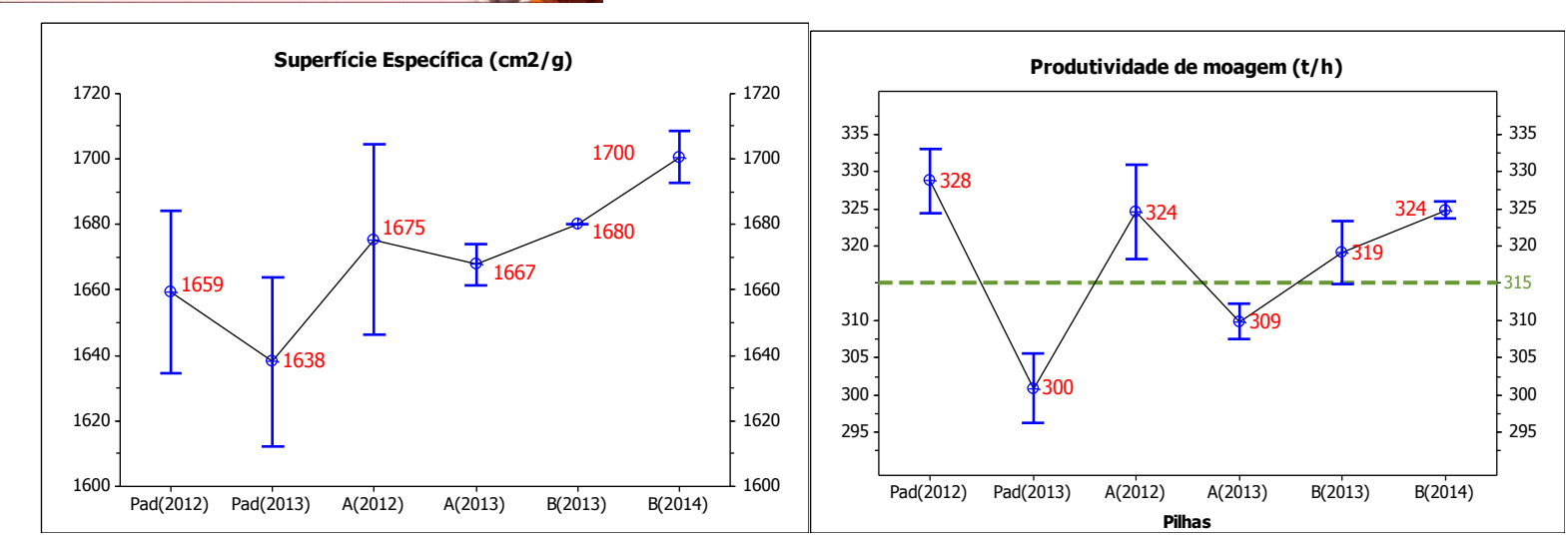

Figura 5. Gráficos de qualidade física pós-moagem (granulometria passante em 0,45mm e superfície específica da polpa retida) e da produtividade dos moinhos da Usina Itabrasco.

Os resultados mostram que grandes diferenças na capacidade da moagem em função da presença de goethita e de hematita martítica nessa ordem, confirmando o trabalho de outros autores. Entretanto, demonstraram também que a presença elevada de hematita especular reduz a taxa de alimentação da moagem secundária.

A tendência de elevação da SE consoante com a elevação da produtividade da moagem demostra o fenômeno relacionado com elevação de Brucutu mantendo o minério II nas mesmas proporções na pilha. Além da razão axial maior do hábito tabular em relação ao granular, as estruturas porosas proporcionam este cenário de acordo com as citações dos autores. A obtenção de SE com maior produtividade da moagem gera reduções de custos consideráveis como energia elétrica e corpo moedor, garantindo massa para produtividade por metro quadro mais elevada do forno das plantas de pelotização [2].

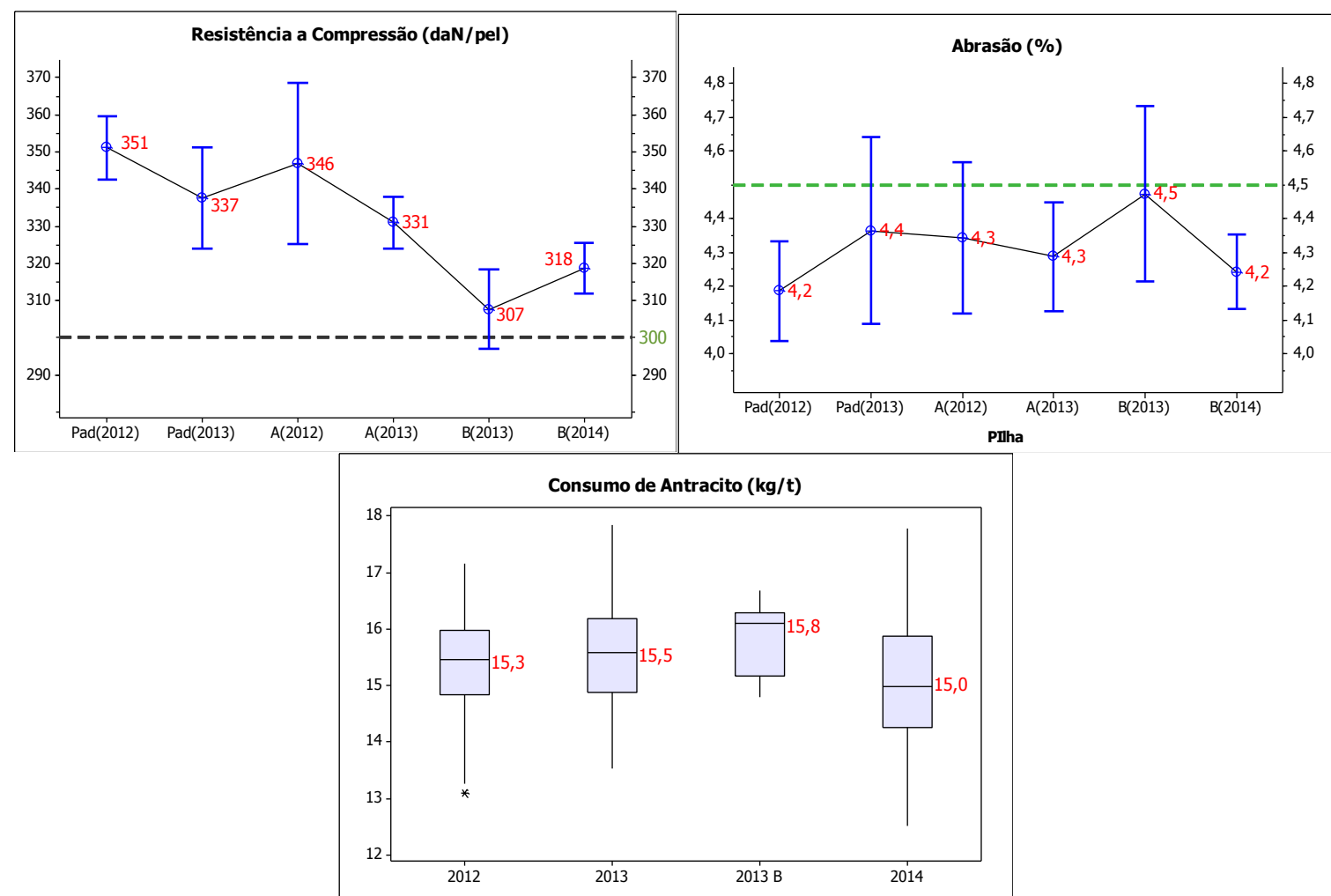

Figura 6. Gráficos de qualidade física da pelota processada no forno da Usina Itabrasco (resistência a compressão e abrasão) e o consumo de antracito.

Os resultados de abrasão mantiveram-se estáveis durante as alterações de mistura de minério. Já o comportamento da compressão ao longo dos anos, vem apresentando

* Contribuição técnica ao 44 Seminário de Redução de Minério de Ferro e Matérias-primas, 15 Simpósio Brasileiro de Minério de Ferro e $2^{\circ}$ Simpósio Brasileiro de Aglomeração de Minério de Ferro, 15 a 18 de setembro de 2014, Belo Horizonte, MG, Brasil. 


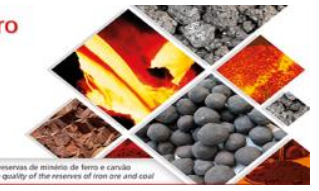

tendência de redução em função da elevação do consumo de combustível sólido (antracito) que modifica a estrutura da pelota ao difundir os voláteis durante o processo de queima.

Entretanto, outro fenômeno foi observado ao manter o percentual de carbono fixo na pelota com a elevação de Brucutu nas misturas de minérios. A qualidade física da pelota (compressão e abrasão) deteriorou substancialmente ao aplicar o mix da pilha B no ano de 2013. Esta ocorrência está relacionada com a obtenção da estrutura duplex (hematita nas bordas e magnetita retida no centro) nas pelotas produzidas com presença em maior escala de goethita, magnetita e hematita secundária descritos por Dwarapudi et al. [8] e Jiang et al. [9]. O ajuste do aporte térmico em 2014 (perfil de temperatura e carbono fixo) adequou as condições de qualidade física, sinalizando uma oportunidade de redução do consumo de combustível.

\section{CONCLUSÃO}

A caracterização mineralógica e microestrutural dos diferentes minérios absorvidos pelo Complexo de Tubarão gerou massa crítica ao corpo técnico para adequar o processo operacional visando absorver o volume mais abundante disponibilizado pela mina de Brucutu.

A elevação deste pellet feed e a manutenção de Mariana nas pilhas de finos de minério proporcionaram obtenção de SE com alta produtividade de moagem em função da participação de estruturas porosas e de hábito tabular em maior escala. O desempenho do parque de moagem juntamente com a adequação de aporte térmico do forno da Usina Itabrasco estão possibilitando oportunidades de redução de custos em termos de energia, corpo moedor e combustível.

Apesar da inversão da maior massa retida em peneiras de maior abertura de malhas, a qualidade física se manteve estável comparando a pilha padrão com a pilha de maior participação de Brucutu. Vale ressaltar que ao longo dos anos esta inversão vem sendo percebida para todas as minas envolvidas.

\section{Agradecimentos}

Agradeço a todos que colaboraram direta e indiretamente neste trabalho. Além da Fundação Gorceix e o corpo docente do Departamento de Geologia e Recursos Minerais da UFOP.

Em especial gostaria de agradecer a todos da Unidade Técnica, Planejamento da Produção e da Usina Piloto/DIPE/Vale Tubarão que empenharam e dedicaram neste trabalho.

\section{REFERÊNCIAS}

1 Roberto BJ. 2010. Influência dos Diversos Tipos Litológicos nas Operações de Concentração da Instalação de Beneficiamento de Brucutu. Escola de Engenharia da UFMG, Universidade Federal de Minas Gerais, Minas Gerais, Dissertação de Mestrado, 11p.

2 Meyer K. 1980. Pelletizing of Iron Ores. Wurzburg, Druckerei K. Triltseh.

3 Sá K.G. 2003. Estudo da Influência da Mineralogia dos Tipos de Minérios da Samarco Mineração sobre a resistência a compressão de Pelotas para Processos de Redução Direta. Ouro Preto, Rede Temática em Engenharia de Materiais, Escola de Minas, Universidade Federal de Ouro Preto, Dissertação de Mestrado.

4 Mourão JM, Stegmiller L. 1990. Influência da Estrutura dos Minérios de Ferro na sua Moabilidade. In: Encontro Nacional de Tratamento de Minérios e Hidrometalurgia, 14, Salvador, Anais, 1: 228-243.

* Contribuição técnica ao 44 Seminário de Redução de Minério de Ferro e Matérias-primas, 15 Simpósio Brasileiro de Minério de Ferro e $2^{\circ}$ Simpósio Brasileiro de Aglomeração de Minério de Ferro, 15 a 18 de setembro de 2014, Belo Horizonte, MG, Brasil. 
5 Rosière CA, Chemale F. 2000. Itabiritos e Minérios de Ferro de Alto Teor do Quadrilátero Ferrífero - uma visão geral e discussão. Geonomos 8 (2): 27-43.

6 Baker LA., Thomas CG, Cornelius RJ, Lynch KS, Armstrong GJ. Effect of Goethite on Production Rate in a Traveling Grate Pellet Plant. Society of Mining Engineers, 1973; 254 : 270-278.

7 Casagrande C. Influência das Diferentes Participações de Pellet Feed Brucutu no Processo de Moagem, Pelotamento e Queima. Relatório Técnico - Vale / DIPE / GEPDP / GAEPP.

8 Dwarapudi S.; Gupta P. K.; Rao S. M. 2007. Prediction of Iron Ore Pellet Strength Using Artificial Neural Network Model. ISIJ International, 2012; 47(1): 67-72.

9 Dwarapudi S.; Gupta P. K.; Rao S. M. 2007. Prediction of Iron Ore Pellet Strength Using Artificial Neural Network Model. ISIJ International, vol. 47, No. 1, ISSN 0915-1559. 67-72.

10 Jiang T, Zhang Y, Huang Z. 2008. Preheating and Roasting Characteristics of HematiteMagnetite (H-M) Concentrate Pellets. Ironmaking Steelmaking, 2008; 35(1), ISSN 0301-9233. 21-26.

11 Midrex Techinology INC. 2012. World Direct Reduction Statistics 2012. Charlotte, North Caroline, USA, 3-5. 